\title{
Punindo a Eva em projetos de lei: a frente parlamentar evangélica em oposição ao aborto
}

\author{
Punishing Eva in law projects: the evangelical parliamentary \\ front in opposition to abortion
}

Danielle Ventura de Lima Pinheiro ${ }^{1}$
Marinilson Barbosa da Silva ${ }^{2}$

\section{Resumo}

A defesa da fé religiosa está presente nos espaços públicos brasileiros, seja numa oração do Pai Nosso, compreendido como suposta 'oração universal' nas Escolas Públicas, seja no Congresso Nacional, com a presença maciça da bancada evangélica com seus posicionamentos pautados nos princípios cristãos. O tema aborto tem sido alvo de discussão mundialmente e a sua legalização é defendida por grupos feministas, em prol do direito das mulheres decidirem sobre os seus corpos. No Brasil, além do respaldo dos estudos da bioética, os políticos da bancada evangélica pautam seus argumentos na sua visão religiosa para justificar a transformação do aborto em crime hediondo ou para legitimar a possibilidade de criar um auxílio financeiro para garantir que as mães estupradas não abortem. Analisar dois projetos de lei criados por este grupo político e voltados para o aborto é o objetivo deste trabalho.

Palavras-chave: Aborto. Frente Parlamentar Evangélica. Patriarcado.

\section{Abstract}

The defense of religious faith is present in Brazilian public spaces, either in a prayer of the Our Father, understood as a supposed "universal prayer" in the Public Schools, or in the National Congress, with the massive presence of the evangelical group with its positions based on Christian principles. The abortion theme has been the subject of worldwide debate and its legalization is advocated by feminist groups for the right of women to decide on their bodies. In Brazil, in

\footnotetext{
${ }^{1}$ Doutora em Educação pelo PPGE-UFPB, Doutora em Ciências da Religião pela PUC-GO (2014), mestra em Ciências das Religiões pela UFPB (2009), especialista em Gestão Escolar pela FAVENI (2017), especialista em Psicopedagogia e graduada em História pela UFPB (2007). É professora de História da rede municipal de João Pessoa (PB) e professora substituta do Departamento de Ciências das Religiões.

${ }^{2}$ Licenciado em Psicologia pela Universidade Estadual da Paraíba (UEPB), Graduado em Formação de Psicólogo pela Universidade Federal da Paraíba (UFPB), Bacharel em Teologia pela Escola Superior em Teologia no Rio Grande do Sul (EST-RS). É mestre em Educação pela Pontifícia Universidade Católica do Rio Grande do Sul (PUCRS) e doutor em Educação pela Universidade Federal do Rio Grande do Sul (UFRGS). Atualmente, é professor Associado pelo Departamento de Habilitações Pedagógicas (DHP) - Centro de Educação (CE) - da Universidade Federal da Paraíba (UFPB), atuando nos cursos de Pedagogia Presencial e a Distância (EAD).
} 
Religare, ISSN: 19826605, v.15, n.2, dezembro de 2018, p.570-584.

addition to the support of bioethics studies, politicians from the evangelical standpoint base their arguments on their religious view to justify turning abortion into a heinous crime or to legitimize the possibility of creating financial assistance to ensure that raped mothers do not abort. Analyzing two bills created by this group and focused on abortion is the objective of this article.

Keywords: Abortion. Evangelical Parliamentary Front. Patriarchate

\section{Introdução}

Atualmente, o aborto é aceito legalmente em caso de estupro, risco de vida da mãe e por decisão do Supremo Tribunal Federal ${ }^{3}$. Alguns defensores do aborto justificam que este se trata de uma questão social, pois enquanto as mulheres ricas permanecem abortando em clínicas especiais e sem risco de morte, as mulheres mais pobres se utilizam de clínicas clandestinas precárias, arriscando suas vidas (EMMERICK, 2007; SAÚDE, 2009).

A Frente Parlamentar Evangélica, composta por 75 deputados e 3 senadores e fundamentada em uma visão religiosa, busca transformar o aborto em crime hediondo e luta contra a flexibilização nos casos já permitidos por leis. Frequentemente, a bancada evangélica conta com o apoio de outras instituições religiosas que se pautam no direito à vida e na bioética para fundamentar seus discursos. A bioética em si já traz consigo um discurso religioso ao apresentar como argumento chave o fato dos homens serem filhos de Deus (WESTPHAL, 2009; MOORE,1998).

Essa visão religiosa em um espaço laico será aqui analisada, a fim de compreendermos como, na contemporaneidade, ela ainda fundamenta as discussões atuais e exerce influência sobre as decisões políticas dos parlamentares brasileiros. Essa permanência do patriarcado, neste debate, permite que se compreenda este estudo como capaz de "desvendar, no discurso

\footnotetext{
${ }^{3}$ Decreto-lei 2848/40
} 
Religare, ISSN: 19826605, v.15, n.2, dezembro de 2018, p.570-584.

dominante, estruturas preconceituosas androcêntricas e, desta forma, desmascarar a objetividade aparente como uma retórica do partidarismo masculino" (PRAETORIUS, 1996, p. 21).

Para tanto, discutiremos aqui as propostas da bancada evangélica, que refletem sobre a flexibilização do aborto, pensando em soluções que garantam o direito do nascituro; refletiremos sobre a sua defesa do aborto como crime hediondo e, por fim, observaremos como nas entrelinhas destes discursos está a visão religiosa, que traz marcadamente um olhar para os papéis sociais cabíveis aos homens e às mulheres na sociedade. Assim, observar-se-á a visão religiosa sedimentando as relações sociais e ocupando os espaços laicos, sob uma visão que, aparentemente, se pauta apenas no olhar para a defesa da vida.

\section{"Bolsa estupro" em questão: proposta da bancada evangélica para garantir o direito do nascituro}

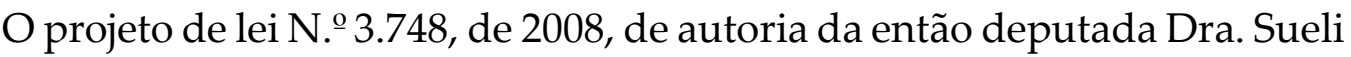
Vidigal (PDT), autoriza a concessão de pensão à mãe que resolva ter a criança nascida de gravidez em decorrência do estupro. Assim, “Art. 1ํㅜ Fica o Poder Executivo autorizado a pagar, mensalmente, pensão à mãe que mantenha, em sua companhia, a criança nascida de gravidez decorrente de estupro, até que complete 21 (vinte e um) anos de idade".

Para tanto, os artigos esclarecem que deve ser feito um cadastramento junto ao Ministério de Assistência Social, apresentando os seguintes documentos: “I - cópia autenticada do registro policial de ocorrência; II - laudo do Instituto Médico Legal; III - cópia autenticada da certidão de nascimento da criança". Orienta-se que na Delegacia os servidores já devem informar às mulheres sobre este direito assegurado.

A justificativa apresentada é que as mulheres vítimas de estupro, ao abortarem, cometem outro crime, previsto no artigo 128 do Código Penal Brasileiro. Além disso, se considera o aborto como uma violência contra seres 
Religare, ISSN: 19826605, v.15, n.2, dezembro de 2018, p.570-584.

indefesos, que têm direito ao esporte, lazer, profissionalização, dignidade, liberdade, convivência familiar e comunitária.

Argumenta-se que o ser humano tem direito à proteção, à saúde, à vida, e à políticas públicas e sociais que garantam o nascimento e o desenvolvimento harmonioso e sadio, de forma digna, como determina a Constituição Federal de 1988.

É interessante observar que a solução para garantir o direito à vida do nascituro se limita ao pagamento de um salário mínimo para a mãe que foi violentada. Não se pensa no estado psicológico da genitora ao conceber um filho não desejado, que é fruto de um ato de violência.

A visão religiosa encontra no financiamento desta criança, por parte do Estado, um mecanismo que se sobressai ao que já está garantido pelo Código Penal, que é o aborto em caso de estupro. Percebe-se, implicitamente, a visão de Deus como Criador, que jamais permitiria que fosse recusado a um ser humano o direito de nascer.

Há, portanto, a introdução de um valor religioso no espaço laico, de tal forma que consegue se pensar em políticas públicas que respaldem a visão religiosa da vida, não se preocupando com as condições sociais e psicológicas dessas mulheres e de seus filhos.

Não se pensa também no contexto sociocultural das mulheres que sofreram estupro, nem na história de vida de cada uma delas. Há, portanto, um olhar restrito ao nascituro, não garantindo o seu bem-estar, pois se pensa apenas em permitir que a criança tenha como se sustentar financeiramente até a maioridade.

Apesar de ficar explícito que essa "bolsa estupro" é apenas uma alternativa para as mulheres que não queiram fazer o aborto, sabe-se que há um preocupação deste se tornar uma regra, ao invés de exceção, e isso é considerado como retrocesso nos direitos das mulheres, perante a existência legal que lhes assegura o direito de abortar em caso de estupro. 
Religare, ISSN: 19826605, v.15, n.2, dezembro de 2018, p.570-584.

É, portanto, a visão de mundo cristã sendo imposta sem considerar a laicidade do Estado, abrindo espaço para projetos de lei fomentados pela bancada evangélica. Centraliza-se no direito de viver do nascituro, sem refletir sobre a situação das mães.

Trata-se de uma visão patriarcal, que naturaliza e romantiza a maternidade, impondo uma gravidez que surgiu de um ato de extrema violência, que é o estupro. Não há complexidade no debate, pois o interesse no direito do nascituro obscurece um contexto de exclusão social que mãe e criança enfrentarão em uma sociedade em que esse mesmo grupo de religiosos defende um modelo tradicional de família, que inclui pai, mãe e filhos, não admitindo outros modelos familiares. Sobre o patriarcado cabe destacar que:

O vasto sistema de dominação que a teologia feminista denomina de "patriarcado" preenche quase sem brechas toda a história da humanidade que nos é conhecida através de testemunhos escritos. Ele abrange tanto formas de organização social pré-estatais como as sociedades segmentárias, além das formas estatais como o Império Romano à época do aparecimento do cristianismo ou as atuais estruturas de Estado e de poder (SCHOTROFF; SCHAUMBERGER, 1996, p. 369-70).

Assim, os valores patriarcais na atualidade são transformados em projetos de lei que partem de uma esfera religiosa que pensa, ao longo dos anos, nas mulheres como donas do lar e nos homens como provedores e que excluem as outras relações familiares. A cultura religiosa é imposta a um contexto plural, sem pensar nas múltiplas relações sociais presentes na atualidade.

É contraditório se estimular as mulheres a terem seus filhos, mesmo vítimas de violência, desconsiderando a visão de mundo patriarcal que considera como mal exemplo para a educação das crianças a ausência da figura paterna ou que não admite que casais homossexuais adotem filhos, uma vez que:

A cultura patriarcal, como sabemos, permitiu a introjeção de uma divisão de comportamentos ligada à divisão social do 
Religare, ISSN: 19826605, v.15, n.2, dezembro de 2018, p.570-584.

trabalho. Há coisas e comportamentos próprios do homem outros próprios da mulher. Em certos aspectos, essa introjeção é a tal ponto profunda que se torna uma espécie de natureza (GEBARA,1989, p. 17).

A busca pela garantia do nascimento de uma criança atribui a mesma uma exclusão social futura, demarcada pela visão de mundo excludente que cria padrões sociais para homens e mulheres, e que não aceitam a figura da mãe solteira.

Há uma prescrição de valores que pertencem a uma visão religiosa de um grupo restrito, que visam universalizar a sua cultura e naturalizá-la como correta a todas as pessoas. A bancada evangélica não está interessada no respeito à diversidade, presente na própria Constituição Federal, e critica deliberadamente aqueles que têm orientação sexual distinta ou que pertencem a outras denominações religiosas.

Art. 5ำ Todos são iguais perante a lei, sem distinção de qualquer natureza, garantindo-se aos brasileiros e aos estrangeiros residentes no país a inviolabilidade do direito à vida, à liberdade, à igualdade, à segurança e à propriedade, nos termos seguintes: VI - é inviolável a liberdade de consciência e de crença, sendo assegurado o livre exercício dos cultos religiosos e garantida, na forma da lei, a proteção aos locais de cultos e a suas liturgias; VIII - ninguém será privado de direitos por motivos de crença religiosa ou de conviç̧ão filosófica ou política, salvo se as invocar para eximir-se de obrigação legal a todos imposta e recusar-se a cumprir prestação alternativa, fixada em lei; IX - é livre a expressão da atividade intelectual, artística, científica e de comunicação, independentemente de censura ou licença; $\S 2^{2}$ Os direitos e garantias expressos nesta Constituição não excluem outros decorrentes do regime e dos princípios por ela adotados, ou dos tratados internacionais em que a República Federativa do Brasil seja parte. (CONSTITUIÇÃO FEDERAL DE 1988, p. 9-11).

A ideia de conversão que marca esse grupo de religiosos permite que, ao invés de se garantir a livre expressão de fé, enquanto figuras públicas, busquem trazer a sua fé pessoal, que é de foro íntimo, para o ambiente público, que deveria 
Religare, ISSN: 19826605, v.15, n.2, dezembro de 2018, p.570-584.

garantir que todas as pessoas tivessem o mesmo tratamento, independente de crença. Isso permite que reflitamos como o espaço público, ao invés de garantir a igualdade entre todos, tem representantes da população que beneficiam apenas o seu grupo, contrariando os interesses dos demais, ao ponto de lutar para transformar em leis aquilo que é inspirado na sua fé pessoal.

Há, explicitamente, uma visão limitada da Frente Parlamentar Evangélica, que se oportuniza da ocupação cargos públicos para defender o direito do nascituro desde a fecundação, sem pensar que, no futuro, esta criança passará por um processo de exclusão social.

Assim, a defesa pela vida como criação divina é a mesma que desqualifica o modelo familiar por ela sugerido, no momento em que, sendo fruto de um estupro, a mãe terá que criar seus filhos sozinha. Este grupo político e religioso sugere à futura mãe solteira, vítima de estupro, que assuma a maternidade em troca de um salário mínimo, sem refletir na discriminação, nos traumas e nas dificuldades que essa mulher enfrentará para conseguir emprego, conviver em uma sociedade marcadamente patriarcal.

Essa visão religiosa vai além dessa busca de garantir o direito à vida a partir da chamada "bolsa estupro", ela luta para punir severamente quem comete este crime. Assim, há uma luta contínua da Frente Parlamentar Evangélica para caracterizá-lo como crime hediondo.

\section{O aborto como crime hediondo: reflexões sobre o projeto de lei $4703 / 1998$}

A bancada evangélica considera branda a punição prevista pelo código penal brasileiro sobre o aborto, que determina prisão de um a três anos em abortos provocados pela gestante, três a dez anos de cadeia para abortos provocados sem o consentimento da gestante e um a quatro anos com o consentimento da gestante ${ }^{4}$.

4 Artigo 124 a 128 do Código Penal Brasileiro (1940) 
Religare, ISSN: 19826605, v.15, n.2, dezembro de 2018, p.570-584.

No Projeto de Lei 4703/1998, observa-se o argumento pautado na visão de que matar o inocente é um crime abominável e uma injustiça e discriminação odiosa. Para tanto, se considera que se matar o nascido é proibido, não se pode matar o nascituro e fazer diferença entre ambos, pois, nesta perspectiva seria tratá-lo de forma distinta, contradizendo as normas constitucionais. Argumentase que o embrião já é uma vida, isso nos faz observar a perspectiva religiosa que endossa essa reflexão e que fundamenta o discurso das lideranças evangélicas.

A argumentação do Projeto de Lei gira ainda em torno do pensamento de que as mulheres que abortam têm sérios problemas psicológicos, conhecidos como Síndrome do Aborto. Assim, há uma justificativa limitada sobre o psicológico da mulher, que não leva em consideração a sua classe social e inviabilidade de dar prosseguimento a uma gravidez indesejada.

No procedimento abortivo, o método da sucção é criticado por arrancar os pedaços da criança e pela sua cabeça ser esmagada com o fórceps. Assim, distingue-se o corpo do bebê do corpo de sua mãe e se demonstra uma preocupação com o direito de viver do nascituro, sem propor nada para garantir a inexistência de preconceitos vindouros pela ausência de uma estrutura familiar nos moldes tradicionais e a necessidade de uma perspectiva inclusiva que permita que esta criança seja respeitada no futuro, enquanto cidadão.

A ideia de crime abominável, injustiça e discriminação odiosa é reveladora da visão pecaminosa que se insere nas entrelinhas do discurso religioso e a mulher que comete tal ato é vista com repugnância. A maior rigidez sugerida pelos evangélicos é para com aquelas que praticam aborto, demonstrando uma busca por punir aquelas que, supostamente, se esquivam da natureza materna feminina. Está implícita a ideia de que o ato de interromper uma vida criada por Deus é algo abominável e pecaminoso. Logo, a visão religiosa paira neste discurso que deseja punir aquelas que estão, nessa perspectiva, indo contra a vontade divina.

Contraditoriamente, essas mulheres, que não podem fazer o aborto para não serem presas, enfrentam dificuldades para se organizar financeiramente, 
Religare, ISSN: 19826605, v.15, n.2, dezembro de 2018, p.570-584.

sofrem com o abandono de seus companheiros e ainda são vistas como mulheres que estão fora de um padrão tradicional, tal como aquelas que foram estupradas.

Diferentemente da mulher estuprada, a mulher abandonada não receberá nenhum tipo de auxílio financeiro do governo e, quando o pai do seu filho não tiver condições de sustentá-lo, terá que depender de creches do governo ou de seus familiares, para que possam trabalhar. Nem sempre essas mulheres conseguem empregos e, nesses casos, elas passam por um processo de marginalização social ainda maior, pois precisarão cumprir as determinações legais, que têm como escopo uma visão de mundo religiosa centralizada apenas no direito à vida do nascituro.

Não há preocupação se esta criança vá, futuramente, entrar no mundo do crime ou das drogas, como meio de sobrevivência, mesmo sabendo que é justamente em alguns dos setores mais conservadores da sociedade que se luta pela menoridade penal para garantir a sua própria segurança. Essa cobrança da sociedade, em relação aos posicionamentos femininos, é compreensível ao considerarmos que, em uma visão androcêntrica:

O homem já se sente responsável pelo simples fato de nascer homem. Por analogia pode-se deduzir que a mulher pelo fato de nascer mulher não tem as mesmas incumbências. Ou seja, o homem produz a coesão social pelo poder e permite a identificação da parte como o todo e estabelece a diferença. Tal forma de conceber o masculino e feminino é típica das culturas patriarcais (LEMOS, 2012, p. 26).

Não se reflete se essas mulheres têm algum suporte de seus companheiros e se vivem em condições precárias. Ignora-se também que se trata de uma questão social e de saúde pública. Isso ocorre porque há uma idealização da maternidade no meio protestante, que a naturaliza como desejo de toda mulher, como veremos adiante. 
Religare, ISSN: 19826605, v.15, n.2, dezembro de 2018, p.570-584.

\section{Para além da bioética: sacralização da maternidade na visão protestante}

Apesar do discurso pautado na bioética, existente nos projetos de lei supracitados, há uma visão religiosa que, historicamente, tem no seu substrato um patriarcado que naturaliza a cultura de que toda mulher deseja ser mãe. Isso é compreensível, ao termo cultura como:

um padrão de significados transmitidos historicamente, incorporado em símbolos, um sistema de concepções herdadas expressas em formas simbólicas por meio das quais os homens se comunicam, perpetuam e desenvolvem seu conhecimento e sua atividade em relação à vida (GEERTZ 1989, p. 103).

Perpetua-se, portanto, na sociedade patriarcal, a visão da mulher como pré-disposta à maternidade, cuja figura de Maria ocupa lugar central, pois esta é vista como modelo de mulher, sendo mãe e virgem, na visão tradicional da cultura ocidental.

Deifelt (2004) chega a ver a mãe de Jesus como santa protestante, pois a idealização da figura feminina, por parte dos evangélicos, traz similaridades com a visão a Igreja Católica, que tem Maria como modelo de mulher.

A pureza, o silêncio e a obediência de Maria são características idealizadas para a mulher protestante. Vale destacar que este olhar para a mãe de Jesus tem uma ótica clássica ${ }^{5}$, pois na atualidade há também outras percepções da figura de Maria, sob a perspectiva da mariologia social e da hermenêutica feminista ${ }^{6}$.

A figura de Maria como ícone para este mundo patriarcal legitima a crítica a uma mulher que não segue este padrão. Vale destacar que, em uma visão tradicional, é impossível se equiparar à figura de Maria, pois raramente uma mulher consegue ser, concomitantemente, virgem e mãe, e ainda assim ter a

\footnotetext{
${ }^{5}$ Sobre a visão clássica de Maria, que é vista predominantemente entre os cristãos, percebe-se que: Maria, a mãe de Jesus, mãe de Deus, tal como é apresentada pelo mundo androcêntrico e patriarcal, não provoca conflitos, mas ao contrário, fortalece as bases culturais desse mundo, na medida em que se tornou também a sua grande mãe (GEBARA, 1987, p 12).

${ }^{6}$ Veja-se: Boff (2006) e Gebara (2009).
} 
Religare, ISSN: 19826605, v.15, n.2, dezembro de 2018, p.570-584.

pureza de Maria. Assim, há um modelo de mulher para sociedade patriarcal que se sobressai às demais mulheres e que, em uma perspectiva tradicional, cabe à mulher tentar se aproximar deste modelo para ter aceitabilidade, principalmente no meio protestante.

Em um espaço laico, as mulheres que cometem o aborto são vistas em oposição a essa figura feminina. Além disso, Maria aparece em oposição à figura de Eva, que é considerada como responsável pelo pecado original, pois é de Maria que nasce o salvador da humanidade, enquanto Eva foi tida como a responsável pela expulsão do paraíso e, no contexto medieval, houve a difusão do pensamento de que: “O seu papel na Queda é tradicionalmente entendido como o mais grave" (DALARUN, 1990, p.35).

Nesta perspectiva, no mito de Adão e Eva, a culpa do pecado original é atribuída à figura feminina, desconsiderando a serpente e Adão, que fazem parte desta narrativa fundante. Dessa forma, tem-se como mito fundante da cultura judaico-cristã a figura feminina como sendo pecaminosa e responsável pelo sofrimento da humanidade e a figura da Maria, seguidora dos moldes patriarcais, vai se opor a este perfil.

É possível fazer uma associação da punição de Eva com o desejo de punir a mãe que provoca o aborto, ao transformá-lo em crime hediondo. Isso evidencia uma divisão entre os perfis femininos, as que são boas mães e aquelas que cometem o crime contra o nascituro, decidindo-se pelo aborto. Classifica-se, nesta perspectiva, a mulher que aborta como similar a Eva, pois como Eva foi responsável pelo pecado original, a mulher que cometeu aborto pecou negando ao nascituro o direito à vida. Enquanto isso, valoriza-se as mulheres que seguem os princípios cristãos.

Chama a nossa atenção a maneira como se traz para a esfera pública os padrões sociais que estão sedimentados pela esfera religiosa. Não se consegue dividir o espaço laico do espaço religioso, de modo que se luta para se legalizar aquilo que se considera sagrado para a sua fé pessoal. Vale destacar que há uma preocupação de não se destacar a ideia religiosa nos projetos de lei aqui 
Religare, ISSN: 19826605, v.15, n.2, dezembro de 2018, p.570-584.

estudados e que o argumento que se repete é o direito à vida do nascituro, desconsiderando o contexto social das mulheres que fazem o aborto, a diferenciação de classe e também o possível abandono dos pais como fatores motivacionais para cometerem tal ato. Essa omissão se dá pelo desejo de mascarar um discurso pautado na bioética, por se ter conhecimento que a proposta está direcionada para um ambiente laico que comporta todas as crenças religiosas e que, teoricamente, não caberia uma percepção religiosa sendo imposta para os demais, tendo em vista a liberdade religiosa prevista na Constituição Federal de 1988.

Essa visão negativa feminina personificada na figura de Eva está presente também na filosofia grega, pois "subordina os atributos femininos da corporeidade e sensualidade aos masculinos do espiritual e racional" (SCHOTTROFF, 2008, p. 52). Dessa maneira:

Na religião e filosofia gregas, as mulheres representavam a poluição associada com o corpo e a sexualidade devido a seu papel de gerar a vida, que traz consigo a ameaça da morte. Platão e Aristóteles menosprezam as mulheres como a encarnação dos perigos suscitados à razão pela sexualidade. Visto acharem as mulheres dominadas principalmente pelas paixões, são consideradas inadequadas para os feitos racionais. Ideias semelhantes surgem nas opiniões cristãs sobre as mulheres e a sexualidade, provenientes nas religiões grega e hebraica (SCHOTT,1996, p. 63),).

A de ideia de pecado, presente na cultura grega, nos faz observar como o patriarcado tem suas raízes em outras culturas anteriores, que tendem a influenciar a cultura judaico-cristã, adotando para si esta percepção de mundo.

Essa naturalização da submissão feminina, e também a exaltação da maternidade, adentra não somente na discussão da bancada evangélica, mas também nas famílias e nas escolas, ao definirem os brinquedos destinados ao público feminino como ligado ao lar e à maternidade, e ao público masculino como ligado ao trabalho e o entretenimento. 
Religare, ISSN: 19826605, v.15, n.2, dezembro de 2018, p.570-584.

A visão patriarcal sedimenta a visão de mundo da sociedade brasileira, que naturaliza aquilo que se entende como cabível ao homem e à mulher, a tal ponto que lideranças evangélicas, ao assumirem cargos públicos, buscam punir aquelas que fogem ao padrão estabelecido pela religião, se recusando a serem mães e cometendo aborto. Assim, “a sociedade patriarcal, cujas primeiras raízes dificilmente se conseguirão detectar, produziu sua antropologia, seu modelo de homem e mulher a partir de maneiras de organizar a sociedade" (GEBARA, 1989, p. 10).

Essas intricadas relações requerem "atenção com relação a uma complexa conjugação de forças econômicas e sociais, formas de produção, ideologias, movimentos políticos e sistemas legais" (CORRÊA, 1996, p. 153).

A sacralização da maternidade se dá a tal ponto que se incentiva a mulher ter o filho, mesmo em casos de estupro. Assim, por mais que se enfoque o discurso na ideia de direito à vida do nascituro, há questões religiosas profundas que induzem os protestantes a se oporem radicalmente ao aborto, mesmo em casos em que ele já foi permitido legalmente.

É, portanto, a esfera religiosa sendo encarada como padrão para todas as pessoas, independente de crença pessoal. Não há como negar, portanto, como o discurso religioso, até hoje, tem grande influência na construção de leis que, em caso de descumpridas, levará o cidadão a ser punido radicalmente.

\section{Considerações Finais}

Analisando os posicionamentos da Frente Parlamentar Evangélica sobre o aborto, a partir do estudo da cultura patriarcal e da hermenêutica feminista, nos fizeram observar como o cristianismo ainda detém influência nos espaços laicos.

É importante destacar que os argumentos da bancada evangélica se pautam no respeito à vida do nascituro e buscam omitir a reflexão religiosa que está presente neste posicionamento, sem destacar a visão que se tem sobre o 
Religare, ISSN: 19826605, v.15, n.2, dezembro de 2018, p.570-584.

papel feminino na sociedade e também sem refletir nas questões sociais que estão por trás de cada aborto cometido

A busca por obrigar o Estado a sustentar a mulher que engravidou, vítima de um estupro, demonstra a visão de todos como sendo filhos de Deus e do caráter inaceitável do aborto. Concomitantemente, a busca por punir quem comete o aborto ao transformá-lo em crime hediondo também demonstra a revolta para com a mulher que não quis dar continuidade à sua gestação.

Unindo-se os estudos da hermenêutica feminista e também da religião, pode-se observar que a ideia de maternidade como sendo da natureza feminina é o que faz com que não se admita o aborto e se tenha o desejo de punir a mulher pecaminosa, que rejeita um ser que ainda não veio ao mundo. É possível pensar também que o discurso religioso é contraditório, porque é comum entre os protestantes a visão tradicional de família, rejeitando, por exemplo, quem não se encaixa em um modelo pré-estabelecido, como os casais homossexuais e as mães solteiras.

Enfim, buscou-se aqui compreender a visão religiosa da bancada evangélica em espaço laico, a partir de um estudo que valoriza a hermenêutica feminista, que pensa sobre o patriarcado como consolidador das relações sociais e que traz Maria como modelo de mulher.

\section{Referências}

BOFF, Clodovis. Mariologia Social: o significado da Virgem para a sociedade. São Paulo: Paulus, 2006.

Constituição (1988). Constituição da República Federativa do Brasil. Brasília, DF:Senado Federal: Centro Gráfico, 1988.

DALARUN, Jacques. Olhares dos clérigos: In:___. História das mulheres: a idade média. Porto: Afrontamento, 1990. V. II.

Decreto lei 2848/1940. Disponível em:< http://www2.camara.leg.br/legin/fed/declei/1940-1949/decreto-lei-2848-7dezembro-1940-412868-publicacaooriginal-1-pe.html> Acesso em: 14/09/2018. DEIFELT, Wanda. María: una santa protestante?. Revista de Interpretación Bíblia Lationoamericana, Quito, n.46, p. 98-112, 2004. 
Religare, ISSN: 19826605, v.15, n.2, dezembro de 2018, p.570-584.

EMMERICK, Rulian. Corpo e poder: um olhar sobre o aborto à luz dos direitos humanos e da democracia. Dissertação (Mestrado em Direito). Pontifícia Universidade Católica do Rio de Janeiro, Rio de Janeiro, 2007.

GEBARA, Ivone; BINGEMER, Maria Clara. Maria, mãe de Deus e dos pobres. Petrópolis: Vozes, 1987.

GEBARA, Ivone; BINGEMER, Maria Clara. As incômodas filhas de Eva na Igreja da América Latina. São Paulo: Paulinas, 1989.

GEBARA, Ivone; BINGEMER, Maria Clara. Uma leitura feminista da Virgem Maria. In: DOMEZI, Maria Cecília; BRANCHER, Mercedes (Orgs.). Maria entre as mulheres: perspectivas de uma Mariologia feminista libertadora. São Leopoldo: CEBI; São Paulo: Paulinas, 2009. p. 9-26.

GEERTZ, Clifford. Interpretação das culturas. Rio de Janeiro: Guanabara, 1989.

LEMOS, Carolina Telles. Maternidade e devoções marianas: âncora na manutenção das desigualdades de gênero. In: SOUZA, Sandra Duarte. Gênero e religião no Brasil. São Bernardo do Campo: Edumesp, 2006.

MOORE, George Edward. Principia Ethica. São Paulo: Ícone, 1998.

PRAETORIUS, Ina. Androcentrismo. In: DICIONÁRIO DE TEOLOGIA FEMINISTA. Tradução de Carlos Almeida Pereira. Petropolis: Vozes, 1996. p. 2122.

PL4703/1998. Disponível em:< http://www.camara.gov.br/proposicoesWeb $>$ /fichadetramitacao?idProposicao=21071 Acesso em: 10/08/2018.

PL3748/2008.

Disponível

em:

https://www.camara.gov.br/proposicoesWeb/fichadet

ramitacao?idProposicao=405056 Acesso em: 15/09/2018.

SAÚDE, Ministério da. Secretaria de Ciência, Tecnologia e Insumos Estratégicos. Departamento de Ciência e Tecnologia. Aborto e Saúde Pública: 20 anos. 2009. Brasília: Ministério da Saúde, 2009. 428 p. (Série B. Textos Básicos de Saúde).

SCHOTT, R. M. Eros e os processos cognitivos: uma crítica da objetividade em filosofia. Tradução de Nathanael C. Caixeta. Rio de Janeiro: Record; Rosa dos Tempos, 1996.

SCHOTTROFF, Luise; SCHROER, Silvia; WACKER, Marie-Theres. Exegese Feminista: resultados de pesquisas bíblicas a partir da perspectiva de mulheres. Tradução de Monika Ottermann. São Leopoldo: Sinodal, CEBI; São Paulo: ASTE, 2008.

WESTHPAL, Euler. O que é bioética. São Leopoldo: Sinodal, 2009.

Recebido em 12-10-2018.

Aprovado em 20-01-2019. 